\title{
Liking and perceived communication potential as determinants of looking at another'
}

GORDON N. GOLDBERG and DA VID R. METTEE, Yale University, New Haven, Conn. 06510

Female Ss talked to two female confederates (Cs), each hidden from the $S$ 's sight behind a one-way window. Ss who believed they could not be seen by the ('s rarely looked at the windows. Ss who believed they could be seen frequently looked, perhaps because they were attempting to communicate something to the Cs via their glances. However, the latter Ss did not look more at the window of the C they later said they "liked more, "suggesting that perceived communication does not account for the liking-looking effect observed in face-to-face settings.

Several recent studies of face-to-face interaction provide evidence for a relationship between interpersonal attraction and visual behavior-namely, the more attracted one person is to another, the more often the first person looks at the eyes of the other while interacting with him. This effect has been found in studies in which Ss interacted simultaneously with two other persons (Efran, 1968; Efran \& Broughton, 1966; Exline \& Winters, 1965, Study 2) and in studies in which Ss interacted with only one other person at a time (Exline \& Winters, 1965, Study 1; Goldberg, Kiesler, \& Collins, 1969; Kleck et al, 1968).

Two explanations for this liking-looking relationship can be derived from current views of visual behavior. Exline (Exline \& Winters, 1965) regards an S's glances at another person's eyes as communicative acts which indicate the S's "willingness to share affective involvement" with the person. On the assumption that more attraction to another person makes the $S$ more willing to become "affectively involved" with the person, one can derive the prediction that more attraction will lead - to more looking-looking assumed to be communication of "acceptance of affective involvement." This approach views the $S$ as sending messages via his glances. In contrast, Efran (Efran, 1968; Efran \& Broughton, 1966) regards an S's glances at another's eyes as information-seeking acts motivated by a desire for social approval. On the assumption that more attraction to another person makes the $S$ expect to see more signs of approval from this person, one can again derive the prediction that more liking will lead to more looking-looking assumed here to be an attempt to obtain a view of smiles and friendly nods. This social-approval notion views the $\mathrm{S}$ as receiving messages via his glances.

The present study tested the communication hypothesis by examining the visual behavior of Ss confronted with two persons hidden behind one-way windows. Some of the Ss were led to believe that these persons could see the $S$ and any glances she might direct at their windows. These Ss should thus have perceived that the potential existed for communicating a "willingness to share affective involvement" with the persons behind the one-way windows. These Ss could realize this potential simply by looking at the one-way windows, and the communication hypothesis predicts more looking at the window of the better-liked person. The information-seeking hypothesis, however, does not apply and could not account for such a finding, since the Ss could not see the others behind the windows and so could not receive information by looking at the windows-they were limited to sending information.

\section{METHOD}

Female nursing students who volunteered to serve for pay in a study on "personality" were run individually by a male $\mathrm{E}$. The $\mathrm{E}$ first explained that he was trying out a testing procedure he might use for a new kind of personality test. He said the procedure normally required the $S$ "to try as hard as possible to behave in some particular way"-for example, to appear as solemn or as lonesome as possible-while talking to two college girls whom the $\mathrm{E}$ had hired. The present $S$, however, was in a control condition, the $\mathbf{E}$ stated, and was simply to behave naturally when talking to the two girls, who would be present to "see what difference it makes when the $\mathrm{S}$ has an audience" and to see if they could guess how the $S$ was trying to act.

The $E$ then left the room on a pretext, taking with him from an adjacent room one of two female confederates (Cs) who were ostensibly the girls the $\mathrm{S}$ was to talk to.

The other $C$ next wandered into the room, apparently spontaneously, and engaged the $S$ in friendly face-to-face conversation for $3 \frac{1}{2} \mathrm{~min}$. This procedure provided an attraction manipulation similar to that used by Efran \& Broughton (1966): one $C$ became the $S$ 's acquaintance, while the other remained a stranger to her.
When the $\mathrm{E}$ and the other $\mathrm{C}$ returned, the $E$ introduced the $S$ to this $C$. Then in the adjacent room, he seated the $S$ in an isolated chair while the $\mathrm{Cs}$ took their places in front of the $\mathrm{S}$, one off to her left at a small angle, the other off to her right at the same angle. Each of the Cs sat behind a table, facing the $S$, with her head and shoulders inside a box resting on the table. A one-way window, $11 \times 7$ in., on the front of each box, about 60 in. from the $S$, allowed each $C$ to see the $S$ but prevented the $S$ from seeing the $C$ s. The E stated that the two girls were covered by the boxes and instructed not to speak so they could not influence the $S$ though still providing her with an audience. "This is a way of making things the same for all Ss," the Eexplained.

The E then stated that sometimes the girls were allowed to see the $S$ and sometimes they were not, and, after consulting a list, he announced either that the $S$ would be seen or that she would be unseen. For five of the nine $S s$ in the seen condition and four of the six in the unseen condition, the $\mathrm{E}$ and $\mathrm{Cs}$ did not know the condition until this moment. If the unseen condition was to be run, the $\mathrm{E}$ placed a cardboard shield over the inner surface of each of the one-way windows, which were slanted out to leave an opening at the top for this purpose. The Cs, however, secretly raised these shields to give an unobstructed view of the $S$.

The $E$ then gave the $S$ a series of questions written on index cards. "The questions are here," he said, "to give you a chance to talk to the two girls and let them get to know you." While the $S$ answered the questions, each C operated a tally counter and cumulative stopwatch to record her judgments of the number and total duration of the glances the $S$ appeared to direct at her window. This method has been shown to be highly reliable (Goldberg, Kiesler, \& Collins, 1969).

At the end of the $5 \mathrm{~min}$, the $\mathrm{E}$ returned and took the $S$ back to the first room, where she filled out a questionnaire which the E said the two girls would not see.

Over the course of the study, three different $C s$ played each of the roles of acquaintance and stranger. The side on which the acquaintance was seated (S's left or S's right) and the name the acquaintance used ("Anne" or "Linda"; the stranger always took the other name) were counterbalanced. To assure that the $S$ knew which side the acquaintance sat on, the $C s$ wore name tags, the name each $\mathrm{C}$ was currently using was written on a sign in front of the box covering her, and the $E$ pointed out to the $S$ which box covered "the girl you had a chance to talk with."

\section{RESULTS}

Seen Condition

In the seen condition, the attraction manipulation was apparently successful. On 
the questionnaire administered at the end of the study, the nine Ss indicated significantly greater "liking" for the acquaintance than for the stranger (means of 16.3 vs 10.7 on a 19 -point scale; $t_{8}=8.25, p<.01$; all nine $S s$ indicated greater "liking" for the acquaintance). Moreover, the Cs reported that the visual behavior of all Ss in this condition appeared normal. The Ss' glances at the two windows were, for the most part, rather brief but steady fixations. The glances appeared to be deliberate, not accidental, and the Ss did not let their gaze wander over the windows. The timing of the glances in relation to the S's concurrent utterances did not seem unusual in any way.

Nevertheless, no liking-looking relationship emerged in the seen condition. During the 5-min measuring period, the Ss spent an average of $23.4 \mathrm{sec}$ gazing at the window through which the acquaintance was looking, and about the same time, $24.0 \mathrm{sec}$, gazing at the stranger's window $(t=0.16)$. It should be noted, however, that many of the Ss showed a definite visual preference for one $\mathrm{C}$ or the other. The absolu te differences in looking times for the nine Ss were $0,3,4,5,11,11,12,15$, and $23 \mathrm{sec}$. But three of the Ss preferred to look at the acquaintance and six at the stranger, resulting in the mean signed difference of less than 1 sec noted above. ${ }^{2}$

\section{Unseen Condition}

In the unseen condition, the manipulation check did not indicate a reliable difference in liking for the two $\mathrm{Cs}$ (means of 13.2 vs 12.2 on a 19-point scale for acquaintance and stranger, respectively; $t_{5}=1.22$; four of the six Ss indicated equal "liking" for the two Cs). This nonsignificant difference was significantly less than that obtained in the seen condition [interaction $F(1 / 13)=18.83, p<.01]$. Moreover, the Ss' visual behavior did not generally appear normal; glances from four of the six Ss were judged accidental. The six $S s$ in this condition spent an average of only $4.6 \mathrm{sec}$ looking at the acquaintance's window and $2.2 \mathrm{sec}$ looking at the stranger's. Just as in the seen condition, these means were not significantly different $(t=1.18)$.

\section{DISCUSSION}

\section{Normal Visual Behavior}

An individual engaged in face-to-face interaction typically looks intermittently at the other person's eyes. This normal visual behavior occurred here in a purified situation, the seen condition, in which the $S$ could not receive information by looking in the other's direction. The behavior thus could not plausibly have been motivated by a desire to obtain information, but could well have been the result of Ss' desires to communicate something via their glances. The inference that a desire to communicate did motivate the looking is strengthened by the results in the unseen condition. Here Ss did not, presumably, believe they could communicate via their glances and did not, in general, look at the Cs' windows. Were the looking in the seen condition merely the result of Ss'.role-playing or pretending they could obtain information, it should also have occurred here, and it did not.

Liking-Looking Relationship

Though the visual behavior of the $S$ s in the seen condition seems to have been motivated by a desire to communicate, there was no consistent tendency for them to send more messages to the better-liked $C$ (i.e., to look more at her). Perhaps this was so because some Ss were more interested in establishing a positive relationship with the less-well-liked $\mathrm{C}$ than in maintaining the one they had established with the better-liked $C$, and believed the messages they sent via their glances at the former $C$ could help attain this goal. In the seen condition studied here, such a situation could easily persist for the duration of the encounter. But in normal face-to-face interaction, the $S$ receives as well as emits information when he looks at another. The information received from glances at a better-liked person is apt to be more positively valenced than that received from the other person, as the information-seeking hypothesis suggests. In this situation, the tendency for some Ss to look more at a less-well-liked person may eventually be overridden by a tendency to look more at a source of more positive information-unless, of course, it becomes apparent that the attempt to create a positive relationship promises to be successful.

This reasoning suggests that both the desire to communicate and the desire to obtain information may motivate looking in face-to-face interaction, with the latter desire the one usually responsible for the liking-looking relationship. ${ }^{3}$ This reasoning also suggests that a group of Ss may show no consistent visual preference early in a face-to-face encounter, but later in the interaction may come to look more at the better-liked person. That is, as the positive valence of the information obtained from glances at the better-liked person increases and as the $S$ perceives the attempt at establishing a positive relationship with the other person to be failing. S's glances may be increasingly directed at the better-liked individual. Previous studies of face-to-face interaction may have failed to break their data in to brief enough recording intervals to have detected this effect. 4

\section{Attraction Differences}

The expected difference in liking for the two $\mathrm{Cs}$ appeared on the questionnaire administered at the end of the study in the seen condition but not in the unseen condition. The lack of a difference for the unseen Ss may have occurred because these Ss rarely looked at either $C$. Without repeated reminders that one $\mathrm{C}$ was an acquaintance and the other a stranger, an initial difference in attraction to the two may simply have disappeared.

\section{REFERENCES}

EFRAN, J. S. Looking for approval: Effects on visual behavior of approbation from persons differing in importance. Journal of Personality \& Social Psychology, 1968, 10, 21-25.

EFRAN, J. S., \& BROUGHTON, A. Effect of expectancies for social approval on visual behavior. Journal of Personality \& Social Psychology, 1966, 4, 103-107.

EXLINE, R. V., \& WINTERS, L. Affective relations and mutual glances in dyads. In $S$. $S$. Tomkins and C. E. Izard (Eds.), Affect cognition, and personality. New York: Springer, 1965. Pp. 319-350.

GOLDBERG, G. N., KIESLER, C. A., \& COLLINS, B. E. Visual behavior and face-to-face distance during interaction. Sociometry, 1969, 32, 43-53.

KLECK, R., BUCK, P. L., GOLLER, W. L. LONDON, R. S., PFEIFFER, J. R., \& VUKCEVIC, D. P. The effect of stigmatizing conditions on the use of personal space. Psychological Reports, 1968, 23, 111-118.

\section{NOTES}

1. Thanks are due to Anne M. Perno for her contributions to both studies reported here. Miss Perno's work was financed by an NSF undergraduate summer research grant.

2. In a pilot study which used a different attraction manipulation, the same four phenomena were also found in a seen condition (an unseen condition was not run). The $10 \mathrm{Ss}$ indicated greater "liking" for the $\mathrm{C}$ they were expected to prefer-one whose written feedback to the $S$ after an initial session indicated a favorable first impression of the $S$, in contrast to the other $C$ 's unfavorable impression (means of 10.1 vs 7.9 on a 15 -point scale; $t_{9}=2.62 ; p<.05$ ). Again visual behavior appeared normal despite the one-way windows. Again no liking-looking relationship emerged (means of $16.2 \mathrm{sec}$ vs $17.6 \mathrm{sec}$ for looking at the favorable and unfavorable $\mathrm{Cs}$, respectively, in a 3-min period; $t=0.36$ ). And again some of the Ss showed a definite visual preference. The absolute differences in looking times for the nine Ss with complete data were $1,2,3,3,5,6,11,11$ and $17 \mathrm{sec}$. Five Ss looked more at the favorable $\mathrm{C}$. four looked more at the unfavorable $C$.

3. It is possible, of course, that because of something special about the present study the liking-looking relationship would have failed to occur in a face-to-face situation, just as it failed to occur in the seen condition. This seems unlikely, though. Variation in the attraction manipulation used here made no difference; the effect failed to occur in a seen condition in both the pilot and the main study. Moreover, the effect is not a delicate one in face-to-face conditions; it has appeared repeatedly (see references above)

4. The argument advanced here does not depend on the assumption that $S$ perceived her glances at a $\mathrm{C}$ to be communicating her "willingness to share affective involvement" with the C. It remains to be determined exactly what $S$ thinks $S$ is communicating and how this content and the desire to communicate it relate to attraction to the other. It also remains to be determined what, in fact, is communicated, i.e., what inferences an $S$ draws from another's visual behavior toward the $S$ or toward a third person. 